\title{
Toward a Sustainable Community-based Enterprise: Organizational Architecture and Performance
}

\author{
Soviana Soviana ${ }^{1, *}$ \\ ${ }^{1}$ Justus Liebig University, Giessen, Germany \\ *Correspondence: Institute of Farm and Agribusiness Management, Justus Liebig University, Senckenberg Str. 3, \\ 35390 Giessen, Germany. E-mail: s.soviana@yahoo.com
}

Received: November 5, 2014

Accepted: November 16, $2014 \quad$ Online Published: December 10, 2014

doi:10.5430/mos.v2n1p72

URL: http://dx.doi.org/10.5430/mos.v2n1p72

\begin{abstract}
Responding to the lack of understanding of community-based enterprise (CBE), this paper aims to pursue a sustainable CBE-model by identifying the organizational architecture and performance of existing CBEs, as well as finding out aspects that influence the CBEs' success. A case-survey of 34 cases is conducted to bridge the gap between the individuality of case-study reports and a better generalization of knowledge. Ten hypotheses are developed and tested using Partial Least Square and Ordered Logistic Regression methods. Descriptive statistics show that the contextual situation, organizational architecture, and performance of CBEs are far from uniform. The CBEs' performance is sustainable since generally they indeed bring economic, social, as well as environmental improvements. Nevertheless, the sustainability of organizational architecture is rather fragile since almost all CBEs' activities are not free from outsiders' intervention and in many cases 'smaller group of individuals on behalf of the people' still becomes the driver of CBEs.
\end{abstract}

Keywords: community-based enterprise; organizational architecture; performance; case-survey; ordered logistic regression; partial least square

\section{Introduction}

For decades, especially in developing countries, the government has been seen as the one responsible to tackle environmental and poverty problems. However, past experiences showed a lack of success of such a paternalistic approach (Mappatoba, 2004) due to community's over-reliance on continuous external supports and community's low survivability after the phasing-out of intervention programs. During the last three decades, community-based enterprise (CBE) has been increasingly acknowledged as a sustainable way to maintain autonomy of rural and indigenous communities (Orozco-Quintero \& Davidson-Hunt, 2010). As an example, a successful CBE in India, producing and selling jasmine flowers, has helped to alleviate a whole region (about 6 villages or 6000 households) from extreme poverty and it has proved itself robust to recessions and political changes (Handy, Cnaan, Bhat, \& Meijs, 2011). If such a successful CBE-model can be implemented in a wider range, then it may become an answer for poverty alleviation and sustainable development around the world. However, some questions remain. Are the existing CBEs actually as sustainable as that example? How are they organized? Which aspects influence the performance?

Organizational architecture(Note 1) can be considered as one of the most influencing factors for shaping performance (Zoda \& Zaheer, 2012; Jost, 2000; Nadel \& Tushman, 1997). However, despite the increasing implementation of CBE-model, a clear understanding of its organization architecture and performance is still lacking. The equivocality is apparent partly in the diverse definitions of CBE, different understandings regarding the degree of community-participation in the CBE, and various assumptions of CBE's success measurement. In defining the CBEs, some authors focus on the commercial nature of CBE (e.g. Odero, 2004; Welsch, 2004), on the distinction of CBE from most conventional businesses (Kerins \& Jordan, 2010), and some others highlight the collective nature of the CBEs' management and ownership, as well as the multiplicity of goals (e.g. Antinori \& Bray, 2005; Manyara \& Jones, 2007; Peredo \& Chrisman, 2006). Peredo and Chrisman (2006: 316) strongly emphasize the strong community(Note 2) participation and control - a CBE is "managed and governed by the people, rather than by 
government or some smaller group of individuals on behalf of the people". In terms of performance, the interpretation and measurement of success depends on from whose perspective it is considered.

The brief description above also shows some common characteristics of CBE, i.e. management and ownership by the community, multiplicity of goals, and community as the beneficiary. However, there is no common understanding as to which extent those characteristics are realized in practice. Some authors have given some efforts to develop the CBE concept (e.g. Peredo \& Chrisman, 2006; Somerville \& McElwee, 2011). Focusing on the forestry sector in Mexico, Antinori and Bray (2005) compare the community forest enterprise to other organization forms. Peredo and Chrisman (2006) concentrate their research on the experiences of CBE in Andean (Peru) and attempt to develop a theory toward CBE. Apparently, reports about CBE's experiences are often in forms of case-study or project report. The singularity nature of case-study findings has led to a difficulty in yielding generalizable concept (Sandelowski, 2004). Nevertheless, the author argues that in order to create a generally applicable concept, an analysis beyond one particular sector or region is essential.

Mansoor, Aslam, Barbu, Capusneanu, and Lodhi (2012: 48) accentuate the importance of having an appropriate organizational structure, namely "to achieve any organization's success as it provides coordination for the organizational process and facilitates them in achieving the desired goals". Looking closer at the organizational aspects of $\mathrm{CBE}$ is essential for developing a sustainable CBE-scheme, clarifying and improving the current $\mathrm{CBE}$ concept, which can further lead to a better implementation of CBE-scheme in practice. For that purpose, this paper aims to bridge the knowledge-gap by founding the analysis on organizational insights and the generalizability-gap by employing a case survey. The objectives of this paper are: (1) to identify the organizational architecture and performance of the existing CBEs and (2) to find out aspects that influence the success of the CBEs.

\section{Theory and Hypotheses}

Despite the importance of performance to judge if an organization is successful (or failed) to achieve its intended goals (Richard, Devinney, Yip, \& Johnson, 2009), defining, conceptualizing, and measuring performance has not been easy and without controversy among researchers (Abu-Jarad, Yusof, \& Nikbin, 2010; Venkatraman \& Ramanujam, 1986). Based on two crucial questions what to measure and how to measure (Dess \& Robinson, 1984; Kanter \& Brinkerhoff, 1981), the author develops customized performance criteria that reflect the multiplicity of CBE-goals, i.e. the improvement in social, economic, and environmental conditions. Implementing proper organization structure and incentive system, organizational architecture serves as a framework to coordinate and motivate resources and efforts of individuals in order to achieve the organizational goals (Rickard, 2006). The research framework used in this paper is illustrated in figure 1.

\begin{tabular}{|c|c|}
\hline Organizational architecture & Performance \\
\hline Organization structure & Improvement of \\
\hline $\begin{array}{l}\text { Community-participation-level (CPL), partnerships with outsiders, and } \\
\text { community-representation in: } \\
\text { (1) performing tasks; (2) providing resources; (3) decision-making }\end{array}$ & $\begin{array}{c}\text { social } \\
\text { economic } \\
\text { environmental }\end{array}$ \\
\hline Incentive system & \\
\hline $\begin{array}{c}\text { Community's willingness to participate after considering the contextual } \\
\text { constraints, the capacity to do the activities, and (in)tangible organizational } \\
\text { rewards }\end{array}$ & $\begin{array}{l}\text { conditions of the } \\
\text { local community }\end{array}$ \\
\hline
\end{tabular}

Source: adapted from Soviana (2013, pp.3)

Figure 1. Research Framework

Organizational architecture arranges how the responsibility and authority inside an organization are allocated among and accomplished by organization members (Child, 1972; Ruekert, Walker, \& Roering, 1985; Teixeira, Koufteros, \& Peng, 2012). In the CBE context, the organization members are (at least formatively, supposed to be) the community members. Community ownership, community support, community-participation in decision-making, as well as 
capacity to manage and operate the CBEs are claimed to be critical for the success (Li, 2006; Manyara \& Jones, 2007; Soviana \& Kühl, 2013; Stone \& Stone, 2011). The logic of participatory concept is that community-participation may foster sense of ownership, which in turn will lead to a supportive attitude and higher commitment to achieve common organizational goals (Karki, 2001). Hypothesis 1 will test whether a higher community-participation-level (CPL) indeed likely leads to a better performance.

\section{Hypothesis 1: The higher the CPL, the better the performance.}

Community-participation can be in various forms. Aligning with the concept of organizational architecture defined above, the community-participation can be categorized into fulfilling responsibility (performing tasks and providing resources) and exercising authority (making decision). It is important to look closer to questions of what kinds of community-participation are frequently practiced and which of them likely leads to good performance. Evan and Appleton (1993) argue that community-participation has often meant as merely providing local labour and materials with limited decision-making authority. Yet, possessing decision-making authority may increase the sense of ownership since people likely feel empowered if something is done by them and not to them (Scanlon \& Kull, 2009) and hence, positively influence performance. Therefore, the author hypothesizes as follow.

Hypothesis 2: CPL in decision-making is more influential in leading to good performance than CPL in other activities (providing capital or performing tasks).

Moreover, the community is likely not acting in isolation. Non-community stakeholders (hereafter: outsiders(Note 3)) might also be involved. Nevertheless, consistent to the participatory concept, in CBE-context the role of community is supposed to be more influential than the outsiders' role in leading to good performance.

\section{Hypothesis 3: CPL is more influential in leading to good performance than outsiders' participation.}

Talking about community is actually a generalization of diverse community members. Community-representation means whether CBEs only involve leaders or elite groups, also include some "ordinary members", or actually involve a majority of community members. Combining the participatory concept and the argument of Peredo and Chrisman (by the people versus on behalf of the people), it can be hypothesized that a high community-representation tends to lead to a better performance. Furthermore, similar to hypothesis 2, the author hypothesizes that community-representation in decision-making is more influential in leading to good performance.

Hypothesis 4: The higher the community-representation, the better the performance.

Hypothesis 5: Community-representation in decision-making is more influential in leading to good performance than in other activities (providing capital or performing tasks).

The community members are likely not voluntarily participating if there is no incentive to do so. According to Atkinson's theory of achievement motivation, the tendency to undertake an activity is defined as "the product of motive, expectancy, and incentive" (Atkinson \& Feather, 1966: 328). In reference to this theory, this paper concentrates on three aspects, namely contextual constraints, the capacity to do the activities, and organizational rewards.

Firstly, regarding contextual constraints, Peredo and Chrisman (2006) imply that the CBE establishment is likely triggered by social and/or economic distress faced by the community. Having few options left, community members will have an incentive to participate in establishing and managing a CBE. Considering that humans are homo economicus (rational and narrowly self-interested actors), the author presume that community members will tend to think about their own economic welfare before other communal or regional issues (social, environmental, or political constraints).

Hypothesis 6: Economic constraint is negatively correlated with CPL.

Hypothesis 7: Economic constraint is more strongly correlated with CPL than other constraints (social, environmental, political).

Secondly, to have the expectation of being able to pursue the necessary, the community members should have the needed means (asset and/or skill) to build and operate a CBE. Peredo and Chrisman (2006: 318) argue that "a critical resource for CBEs is the social capital that exists in a community". According to social capital theory, social capital facilitates the action of individuals in social context (Nahapiet \& Ghoshal, 1998), reduces uncertainty (Fafchamps, 2000), decreases transaction costs (Fussell, Harrison-Rexrode, Kennan, \& Hazleton, 2006; Putnam, Leonardi, \& Nanetti, 1993), and consequently, facilitates efficiency in labour division and innovation, especially in developing countries where supporting institutional conditions are lacking (Noteboom, 2007). Community with strong social capital will have advantage to act collectively (participating in CBE). While asset or skill can be acquired from outside, social capital is embedded in the community. Accordingly, it can be hypothesized as follows. 
Hypothesis 8: The degree of social capital is positively correlated with CPL.

Hypothesis 9: The degree of social capital is more strongly correlated with CPL than the degree of local asset or local skill.

Thirdly, organizational incentives will become a driver of CPL. Consequent to the author's supposition that economic constraint is the main driver of CBE's establishment, hypothesis 10 is proposed.

Hypothesis 10: A high expected economic benefits tends to lead to high CPL.

\section{Methodology}

\subsection{Sample and Procedure}

Evidence obtained from multiple cases is often considered more convincing than that from a single case (Yin, 2009). Given that knowledge about CBE is distributed over numerous individual case studies, this paper applies a case-survey method to bring diverse case-studies under a common conceptual framework for achieving cumulative findings (Lucas, 1974). This method taps from and optimizes the use of prior case-study research efforts and at the same time fulfils the goal of statistical sampling better than a single or a few case-studies, which are usually limited to only four to ten cases (Eisenhardt, 1989). The use of case-survey can go beyond explorative purpose (for merely providing description); it can also be used for theory-building (inductive research) and theory-testing (deductive research) (Hak \& Dul, 2009). For the purpose of the latter, this paper draws from the meta-analysis procedure, pre-determining the variables to be tested and creating a coding scheme systematically and purposefully. Another advantage of this method is its replicability for future research due to its systematic and well documented procedures.

The sampling is planned and executed systematically (Rapley, 2013; Miles \& Huberman, 1994). A computer search using "community-based enterprise" keyword in scientific databases is conducted, including EBSCO Host (using Boolean phrase) and ScienceDirect (search in abstract, title, and keyword fields), as well as donor/development agencies' publications (FAO, The Rights and Resources Initiative, and ANSAB). The search results are refined by omitting overlapping articles and selecting based on inclusion criteria, namely practically describing one or more case(s) (not theoretical/conceptual articles), comprising information about both organizational architecture and performance of CBE, written in English language, and available in full-text.

As the results, 17 articles ( 8 journal articles, 3 conference papers, and 6 working papers/project reports) fulfil all the criteria and are selected for the analysis. They cover 34 cases in agriculture, forestry, and tourism sectors from 12 countries. Since this paper analyses at case-level, the numbers of cases included are more than the number of articles selected. Spreading over a publication period of 1998-2012, the samples are surprisingly few. An alternative keyword-search using "community-based management" would lead to more search results. However, despite acknowledging it as one limitation of this research, the author intentionally insists on using the term "community-based enterprise" in order to completely focus on the CBE issue.

\subsection{Measurements}

Through the coding, the qualitative information is converted into quantitative data, enabling the analysis through conventional statistics. A mix of data is used in this paper, namely macro indices obtained from some international databases, as well as metric and categorical data derived from each case. The contextual constraints (including social capital and local capacity) and the expected benefits are measured using 3-point rating scale $(1=$ disagree, $2=$ partially agree, and $3=$ agree). The statements used as contextual indicators are, for example, "the community lacks of job opportunity", "there is no crucial local conflict", and "the community already has the necessary management skill", while the expected benefits are measured using the same indicators as those for measuring the performance.

Regarding the stakeholders' participation, four stakeholders mentioned earlier are involved (community, government, NGO, and private sector) and three categories of activities are analysed (performing tasks, providing capitals, and making decision). Each of them is measured by several indicators. After dropping indicators with high missing values (more than 17 cases or 50\%), twelve indicators (three in each category) remain. To measure the participation of each stakeholder, those indicators are rated using a 4-point scale $(0=$ no participation, $1=$ low participation, if the participation is marginal, 2 = medium participation, if the participation is quite significant, and 3 $=$ high participation, if the participation is very dominant). The participation-level in each category is the sum values of the four indicators; the participation-level of each stakeholder in one category ranges from 0 to 12 . The overall participation-level is the sum values of participation in three categories; thus, it ranges from 0 to 36.

A 4-point rating scale is also applied for measuring community-representation $(0=$ no representation, $1=$ low representation, where only local leader or elite group is involved, 2 = medium representation, when some 'ordinary' 
community members are involved, and 3 = high representation, if many or all community members are involved). Consistently, the same twelve indicators as used in the participation are employed here.

Several statements are used to measure performance, whether certain goals (e.g. generation of income, improvement of technical and management skill) are achieved by the CBEs. These statements are to be answered with a 3-point rating scale $(1=$ disagree, 2 = partially agree, and 3 =agree). Out of them, five latent-variables of performance are identified. The overall performance is the sum values of those five variables; thus, it ranges from 1 to 15 . However, for a better overview the scale is re-categorized into a 5-point scale. This decision is taken after checking that there is no crucial result's bias due to the re-categorization.

\subsection{Estimation Technique}

Frequency analyses of all variables are conducted (contextual constraints, organizational architecture, and performance). After dropping variables that have high missing values, Principal Component Analysis for categorical data (polychoricpca and factormat using STATA 12 statistic software) are used to identify the latent-variables and respectively, to reduce the number of less relevant variables. The variables used in this paper are the latent-variables resulted from that procedure. Furthermore, to predict the degree of influence of independent variables on dependent variable, Ordered Logistic Regression analysis (ologit), which is appropriate for categorical dependent variable (Powers \& Yu, 2008), are conducted. Given that the participation-level of all other stakeholders is held constant at its mean value, the impact of a stakeholder's participation-level on the probability of achieving successful performance are analysed using prvalue command in STATA. Besides, a cross-analysis using Partial Least Squares (PLS) regression - a variance-based structural equation modelling (Fornell \& Larcker, 1981) - is conducted. PLS offers flexibility because it does not require the data to be normally distributed (Fornell \& Bookstein, 1982) and it is relatively more robust for smaller sample size than other structural equation modelling techniques (Chin \& Newsted, 1999). For the PLS analysis SmartPLS 2.0 software is used.

\section{Results}

\subsection{Descriptive Statistics}

\subsubsection{Context}

As mentioned previously, this case-survey includes 34 cases from 12 different countries, i.e. Botswana, Brazil, Cameroon, Gambia, India, Kenya, Mexico, Namibia, Nepal, Peru, Philippines, and Uganda, covering tourism (9 cases), forestry (10), agriculture (12), and handicraft (3). The CBEs' start-up time is various, ranging from 2 years (3 cases), 3 years (16), 4 years (2), 5 years (2), 6 years (1), 8 years (1), 10 years (2), to 12 years (2); 5 cases provide no information. Similarly, the CBEs' age is very diverse, stretching from 2 years (13 cases) to 70 years ( 1 case). Some CBEs are about 25 years old (3 cases), between 10-16 years (5), and between 3-9 years (10). One case does not specify the CBE's age.

The CBEs are established mostly in countries with relatively high political instability and quite high perceived corruption, but with diverse poverty level. Based on The Economist (2010), the political instability index in almost all of those countries is between 6 and 7.5 (from a scale of 1.2 (low risk) to 8.8 (very high risk)). The corruption perception index (ranging from 0 (highly corrupt) to 100 (very clean)) is mainly between 25 and 48 (Transparency International, 2013). According to the World Bank (2013), the poverty headcount ratio (ranging from $0 \%$ to $88 \%$ ) in those countries is various; in some countries the ratio is quite low (under $10 \%$ ), while in some others quite high (about $40 \%$ ). Furthermore, the finding shows that the government generally supports the CBE framework - partially (16 cases) and fully (11). However, unsupportive governmental action is also identified in some cases, either being indifferent ( 2 cases) or creating disadvantage (2). Three cases do not specify any information on this matter.

Looking closer at the local level, the communities generally have poor societies' characteristics. The communities face economic challenges (30 cases) with few job opportunities and low income. The lack of health services and educational facilities indicates the poor social services of the communities (31 cases). Their livelihood is very dependent on the natural resources at the local area and they tend to have low environmental awareness, which perhaps helps to explain why environmental problems exist at the area (32 cases). Expectation towards economic benefits generated by CBE is to be seen in almost all cases (33 cases), while expected social and environmental benefits only appear in 25 and 28 cases. Some communities are not open toward outsiders' influence. Almost in all cases that provide information about social capital (about 20 cases), it is indicated that the communities share historical bound, the community size enables the establishment of a CBE, they do not face crucial local conflict, and community members are engaged in the local affairs. The communities originally do not possess the necessary management, technical, infrastructure or financial means to establish a CBE in half of the cases. Remarkably, there is at least one active NGO that supports the community in almost all cases. 
4.1.2 Organizational Architecture

Performing tasks

Initiation

$0 \%$

Community

Government

NGO

Private actor

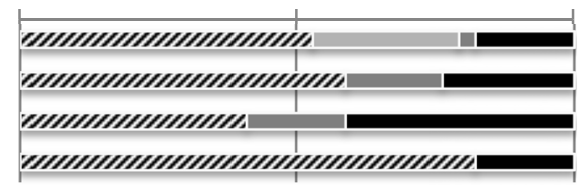

Preparation

$\begin{array}{lll}0 \% & 50 \% & 100 \%\end{array}$

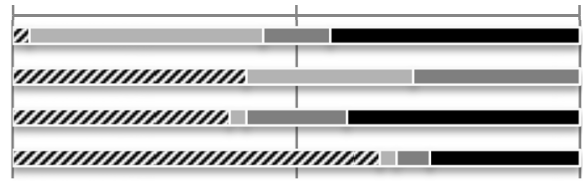

Operation

Evaluation

Community

Government

NGO

Private actor

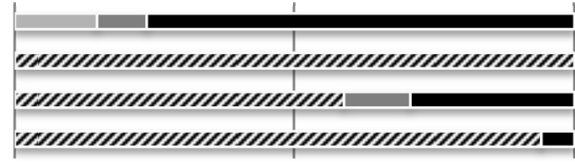

\section{Providing capitals}

$$
\text { Infrastructure }
$$

Community

Government

NGO

Private actor

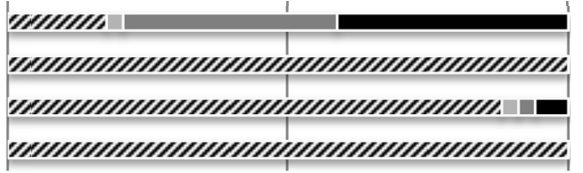

Material

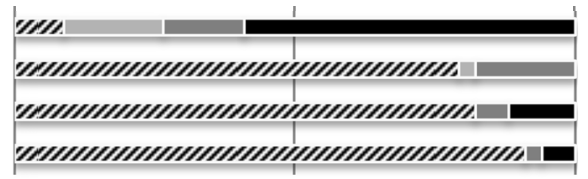

\section{Finance}

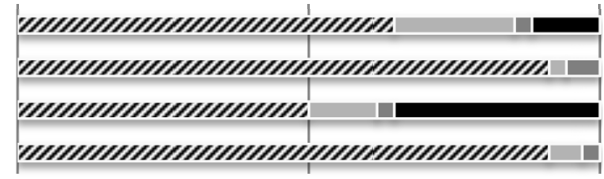

Network

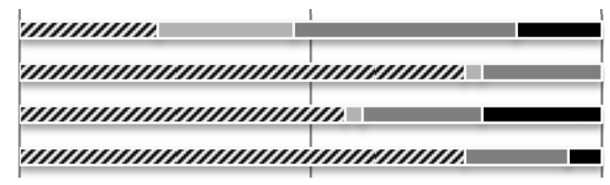

Community
Government
NGO
Private actor

Making decision

\section{Build choice}

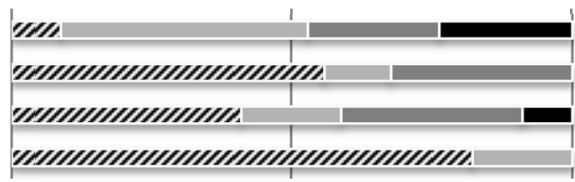

Management choice

Community

Government

NGO

Private actor

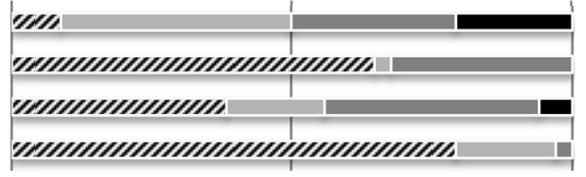

\section{Strategy choice}

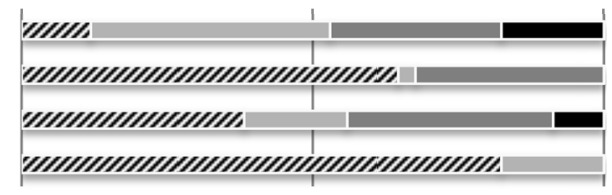

Evaluation choice

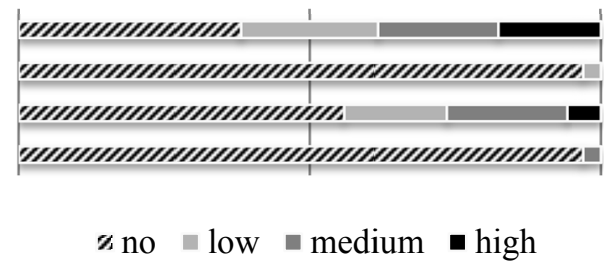

Figure 2. Frequency Analysis: Stakeholders' Participation 
Figure 2 provides an overview of stakeholders' participation in all activities analysed. During the initiation-phase the NGOs (international and local) and governments play more dominant roles than the communities. The private sectors also participate in a few cases. In the preparation-phase, the community-participation is increasing, but the NGOs' and private actors' roles are still quite influential. The community-participation during the operation-phase is very dominant; yet, not completely free from NGOs' intervention. Although little information is available in terms of evaluation-phase, it is indicated that NGOs are again playing a bigger role than the communities. The figure also shows that the communities are the main provider of infrastructure. However, this number should be understood cautiously, since it might be related to the fact that the main financial provider is actually the international NGOs. It is not impossible that the community is able to provide the necessary infrastructure after receiving financial supports from the outsiders. It is easy to comprehend that the communities are dominant in providing material since they likely have the control or user rights over local natural resources. Meanwhile, in terms of networking capacity, the finding shows a mix of participation by different stakeholders. Generally communities are involved in decision-making at all phases; but not free from the intervention of outsiders, especially the (international) NGOs.

As presented in figure 3, the community-representation is high, especially in the operation and providing of materials. The communities are under-represented in terms of initiation, evaluation, finance, and networking. The initiation-phase and the decision-making are coloured by the role of local leaders/elite groups (low representation) and selected 'ordinary' community members (medium representation). In all other aspects, a medium representation is apparent.

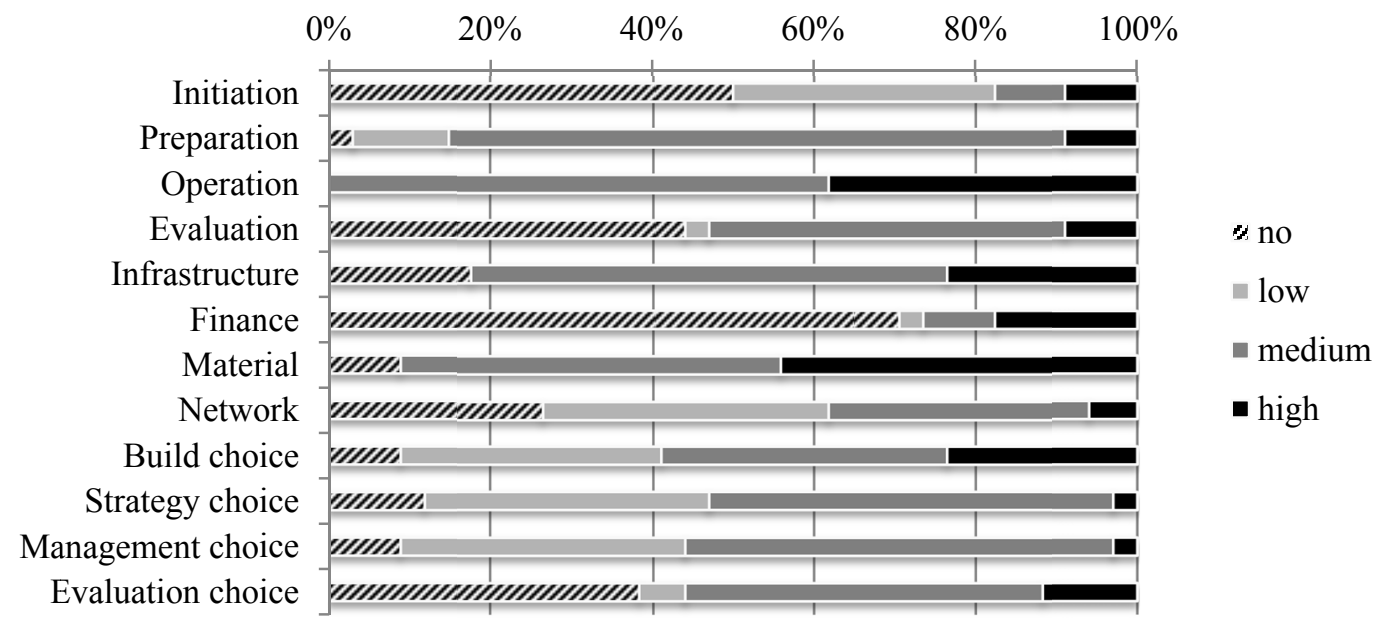

Figure 3. Frequency Analysis: Community-Representation

The CBEs are registered under various legal forms, i.e. association ( 9 cases), enterprise (8), cooperative (1), and trust (1). Seven cases mention that the CBEs are registered, but without specifying under which legal form they are registered, while two cases only imply a kind of informal arrangement among some stakeholders. The rest six cases do not mention any information on this issue. Almost all CBEs apply membership system (31 cases), 20 of which are implementing open membership to all community members and 11 are close membership, restricted only to by-the-entrepreneurs selected community members.

Regarding the availability of local leader, there are 25 valid and 9 missing values. To the statement "there is an influential local leader who can motivate or mobilize the community to establish CBE", 11 cases disagree, 6 partially agree, and 8 agree. Taking the partially agree and agree answers together, it makes up 11 disagree versus 14 agree answers. It implies no clear dominance of one scenario over another.

\subsubsection{Performance}

In many cases the CBEs bring economic, social, and environmental improvements (see figure 4). Aside from using categorical data, economic performance in numbers is captured whenever the cases allow. The revenues generated by the CBEs range widely from 325 US\$ to 11 million US\$. Some cases indicate running at a loss, while some others generate profits, ranging from a few hundred US\$ up to 182 thousand US\$. Perhaps, it is related to how long they have been operating (at the beginning-phase they might need to cover the investment cost) and the way they are coordinated. There is no uniform pattern of employment and benefactors issues. Some CBEs only employ and bring 
benefits to their own few members, while some others employ hundreds of staffs and benefit thousands of inhabitants. Though not every case mentions about the village coverage, it is indicated that the CBEs mostly cover more than one village; in some cases a few and in some others many villages.

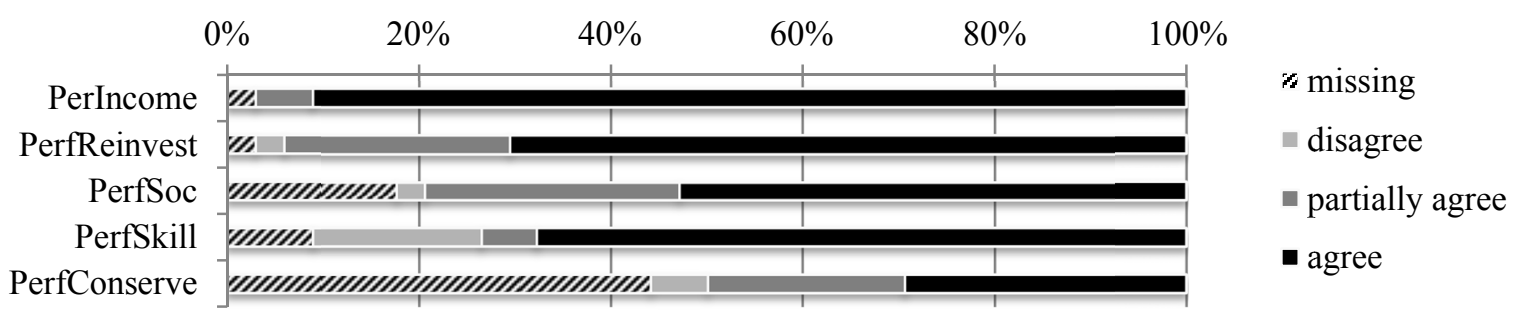

Figure 4. Frequency Analysis: Overview of Performance

\subsection{Correlational Analyses}

The relationship between stakeholders' participation and CBEs' performance are analysed using SmartPLS. Three indicator-variables are assigned to define each of the latent-variables. However, to keep the diagram (figure 5) simple, only those variables relevant for the analysis are reported in this paper, namely five latent-variables (the participation of community, government, NGO, private actor, and the performance) and three indicator-variables (the community-participation in performing task, providing capital, and making decision). The t-value is obtained from bootstrapping process with 2000 bootstrap-samples. Chin (1998) describes $\mathrm{R}^{2}$ values of $0.67,0.33$, and 0.19 as substantial, moderate, and weak, while Hair et al. (2011) suggest another measurement based on the adjusted $\mathrm{R}^{2}$ value, namely $0.25,0.50$, and 0.75 as weak, moderate, and strong. Judging from the $\mathrm{R}^{2}$ value of 0.563 and adjusted $\mathrm{R}^{2}$ value of 0.503 , the author's model can be considered as moderate.

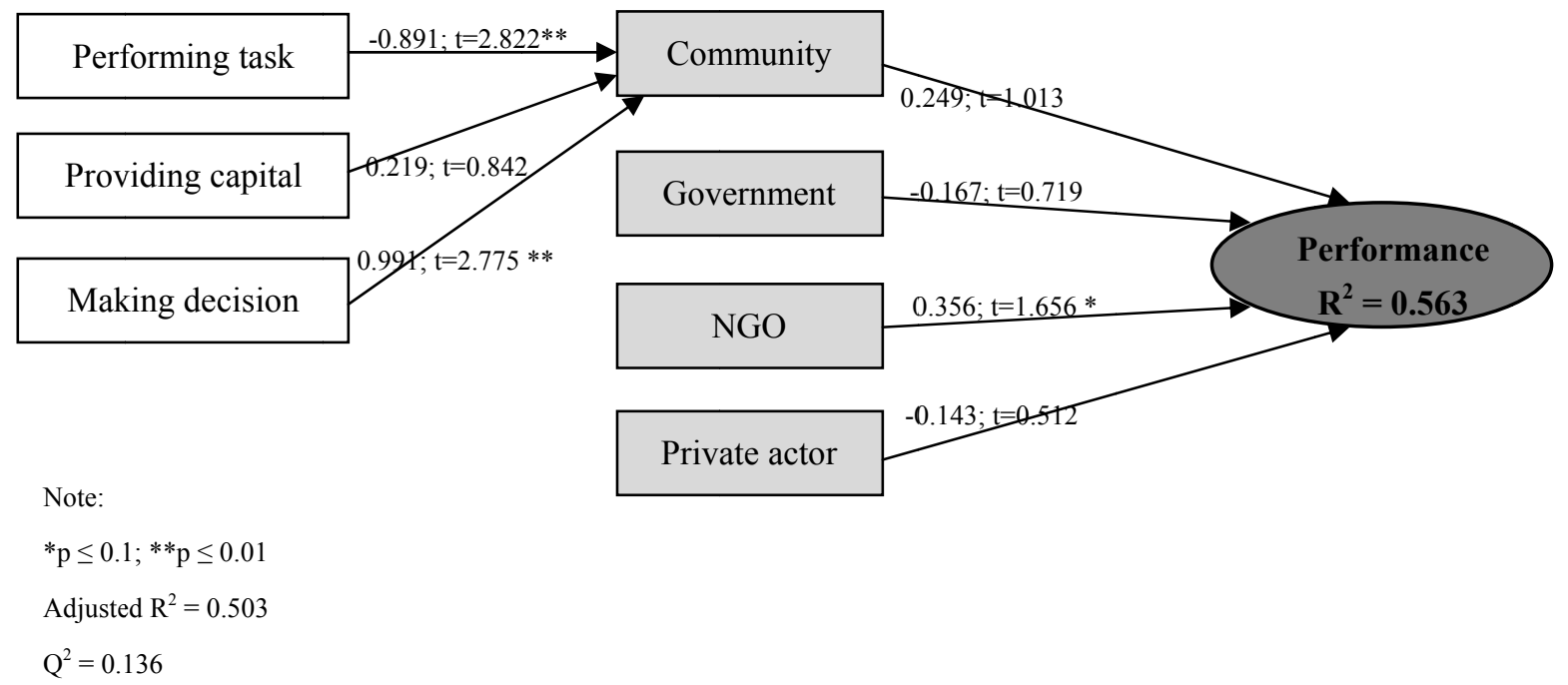

Figure 5. Result of PLS Modelling: Participation-Level - Performance

Figure 6 shows the ordered logistic regression results of the performance of CBE based on four predictors, namely the participation-level of community, government, NGO, and private actor. As mentioned earlier in the methodology, the participation-level is obtained by summing up the value of participation-level in performing task, providing capital, and making decision, while the performance is re-categorized into 5 -point scale $(5=$ very successful). The model itself is significant (Prob $>$ chi2 $=0.0027$ ), which means that at least one of the coefficients in the model is different than zero.

Assessing the inner model of the PLS (figure 5), the result shows that the correlations of participation-level and performance are not that significant. The CPL seems to be positively correlated to performance, while the government and private actor are negatively correlated. However, only the participation-level of NGO is significantly (at $10 \%$ level; $\mathrm{p} \leq 0.098$ ) related to the performance. The regression (figure 6 ) produces similar results. NGO's participation-level is the only predictor that significantly influences the performance $(P>|z|(p-v a l u e)=0.027$; 
$\mathrm{z}(\mathrm{t}-\mathrm{value})=2.21)$. The higher the NGO's participation-level, the higher the odds of getting successful performance. Based on these results, the null hypotheses of both hypothesis 1 and hypothesis 3 cannot be rejected. CPL seems to be positively (but insignificantly) correlated with performance, but high NGO's participation-level is more influential in leading to good performance. Meanwhile, participation-level of government and private actor seem to be negatively (though insignificantly) correlated to performance.

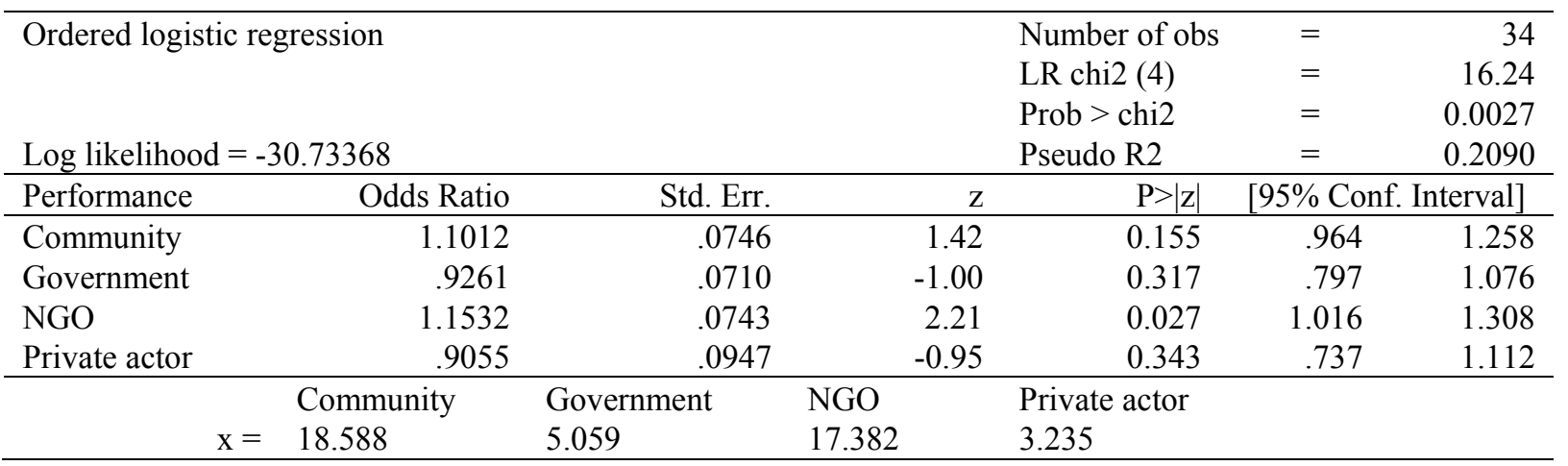

Figure 6. Result of Ordered Logistic Regression: Participation-Level - Performance

Nevertheless, the predictions of hypothesis 1 and hypothesis 3 are supported by the results shown in figure 7 . The diagram shows the influence of each stakeholder's participation-level on the probability of very successful performance, given that all other stakeholders' participation is held constant at their mean values. Apparently, the higher the CPL, the better the performance. Besides, the CPL seems to be more influential in leading CBE to have higher probability in achieving a very successful performance.

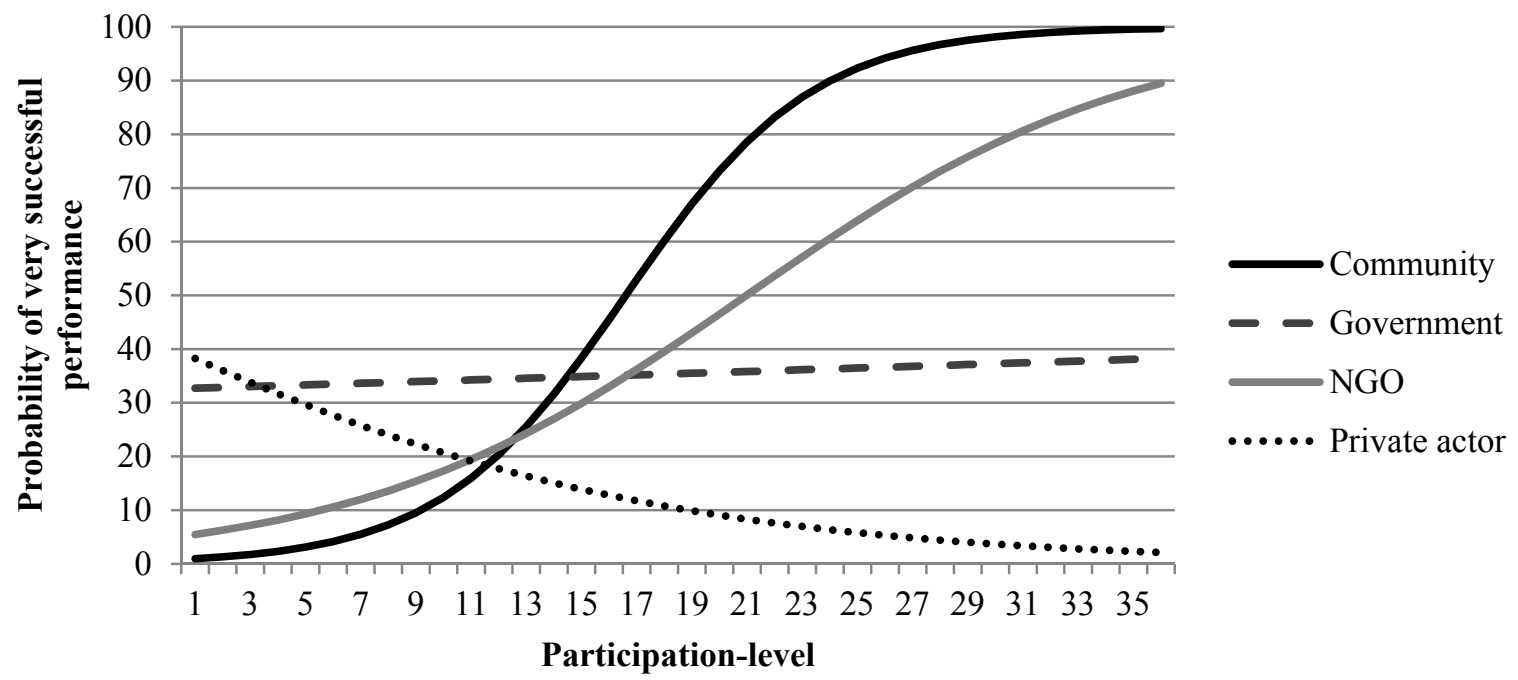

Figure 7. Impact of Participation-Level to Probability of Very Successful Performance

Hypothesis 2 predicts that CPL in decision-making is more influential in leading to good performance than CPL in other activities (providing capital or performing task), which is strongly supported by the result of regression analysis (figure 8). The CPL in decision-making is significantly and positively correlated to performance (t-value $=2.58 ; \mathrm{p}=$ 0.01). In performing task, the CPL is also significantly associated to performance, but negatively. An insignificant positive association is indicated for CPL in providing capital. Similar results are produced by the outer-model of PLS analysis. The path-coefficient of the participation in decision-making is statistically significant at $1 \%$ level $(0.991 ; \mathrm{p}$ $=0.006)$. The CPL in performing task is negatively associated at a $1 \%$ significance level $(-0.891 ; \mathrm{p}=0.005)$, while the CPL in providing capital is positively, but not significantly, associated $(0.219 ; \mathrm{p}=0.400)$.

The result of regression analysis confirms the prediction of hypothesis 4, that the higher the community-representation, the better the performance. The community-representation is positively (and significantly) influences the performance ( $\mathrm{t}$-value $=2.93 ; \mathrm{p}=0.003$ ). The prediction of hypothesis 5 is approved by the regression analysis (figure 9). The result shows a highly-significant positive association between the community-representation 
in decision-making and performance ( $\mathrm{t}$-value $=3.16 ; \mathrm{p}=0.002$ ), while the association of representation in both performing task and providing capital with performance are insignificant.

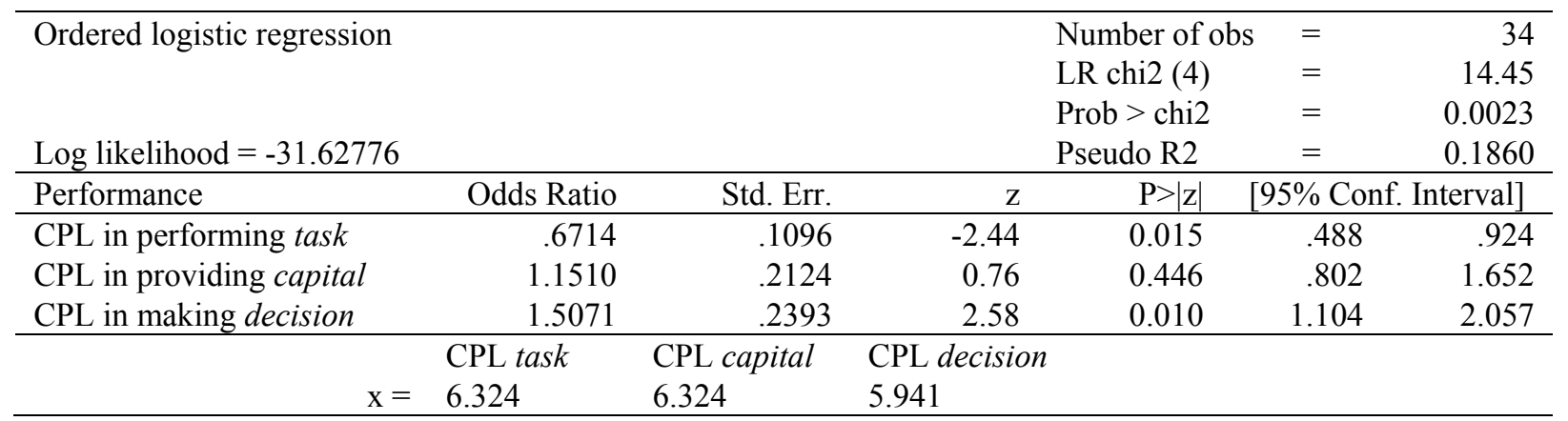

Figure 8. Result of Ordered Logistic Regression: CPL - Performance

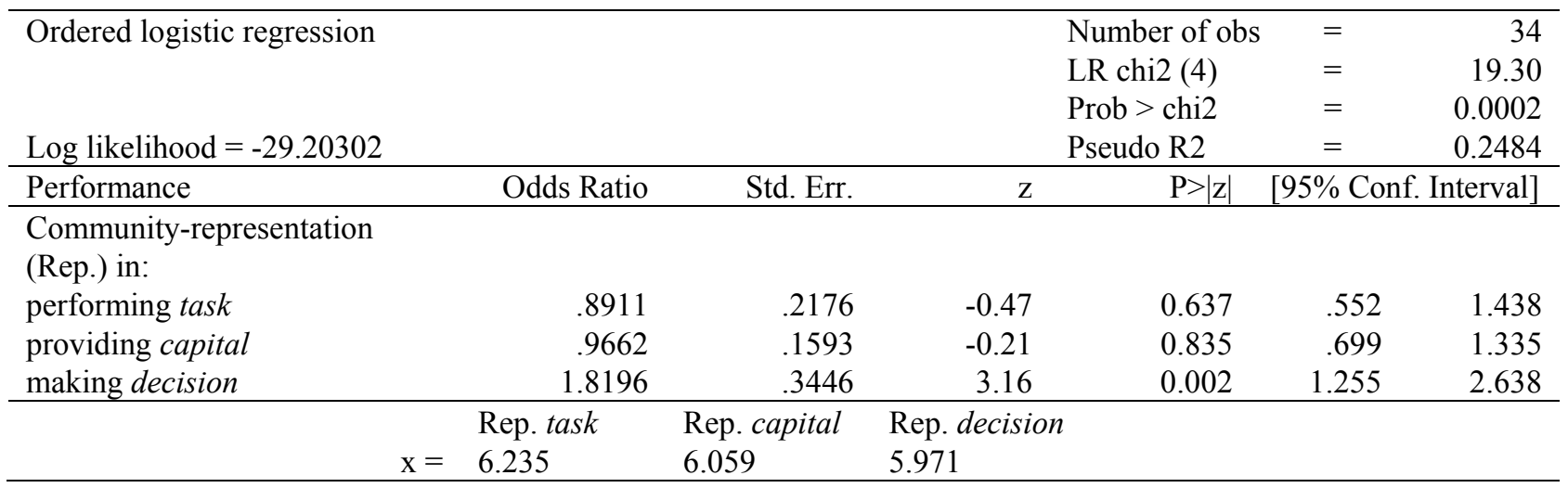

Figure 9. Result of Ordered Logistic Regression: Community-Representation - Performance

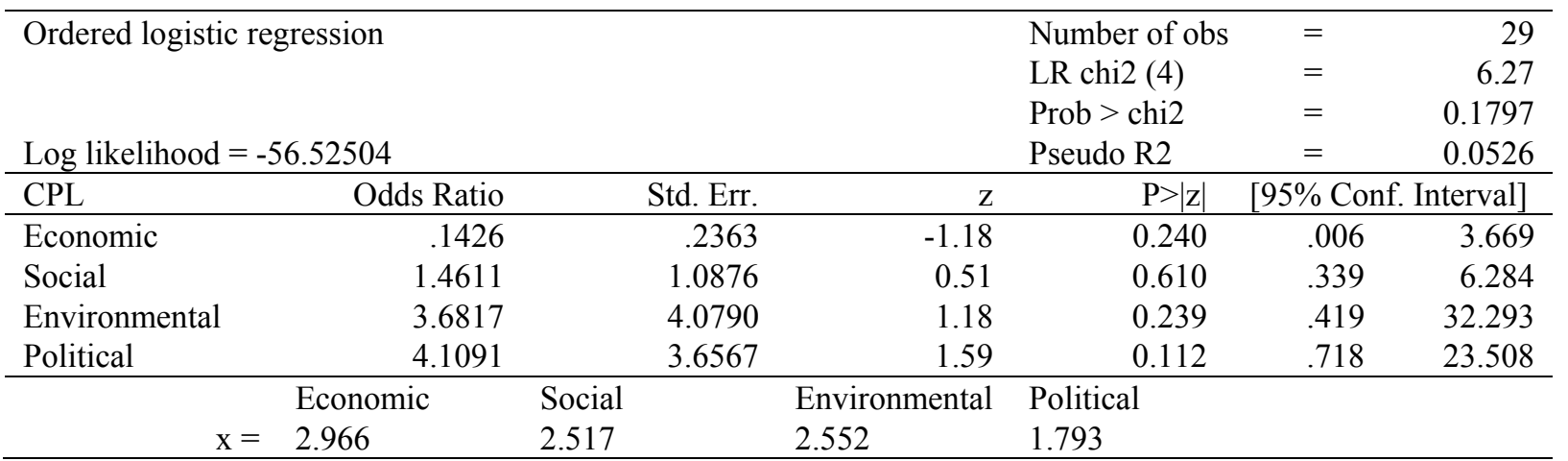

Figure 10. Result of Ordered Logistic Regression: Contextual Constraints - CPL

Figure 10 shows the regression result to test hypothesis 6 and hypothesis 7 . Hypothesis 6 predicts that economic constraint is negatively correlated with CPL, while hypothesis 7 estimates that economic constraint is more strongly correlated with CPL than other constraints (social, environmental, and political constraints). Judging from the regression result, the null hypotheses cannot be rejected since the model's significance is higher than 0.05 (Prob > chi $2=0.1797$ ), which means that there is in fact no effect of the predictor variables on the dependent variable. The correlation of economic constraint with CPL is indeed negative, but it is not significant (t-value $=-1.18 ; \mathrm{p}=0.240$ ). Thus, the economic constraint is not necessarily more strongly correlated with CPL than other constraints.

Meanwhile, the significance level of the model assessing the local capacity and CPL (figure 11) is very high (Prob > chi $2=0.0000$ ). It means that at least one of the regression coefficients in the model is not equal to zero. Local asset is negatively (but insignificantly) correlated to CPL. Both social capital and local skill are significantly associated with CPL. Hypothesis 8 can be accepted since the degree of social capital is indeed positively and significantly correlated with CPL. The impact of local skill (t-value $=3.61)$ on CPL is greater than that of the social capital 
$(\mathrm{t}$-value $=1.92)$. Hence, hypothesis 9 , which predicted that the degree of social capital is more strongly correlated to the CPL than the degree of local asset or local skill, cannot be proven true.

Unfortunately, hypothesis 10, predicting that high expected benefits tend to lead to high CPL, cannot be tested due to multicollinearity during the running of ordered logistic regression. Based on the result of PLS analysis the impact of expected benefits on CPL is very insignificant compared to that of other coordination aspects.

\begin{tabular}{|c|c|c|c|c|c|c|}
\hline \multicolumn{4}{|c|}{ Ordered logistic regression } & Number of obs & $=$ & 28 \\
\hline & & & & Prob $>$ chi 2 & $=$ & 0.0000 \\
\hline \multicolumn{4}{|c|}{ Log likelihood $=-44.66538$} & Pseudo R2 & $=$ & 0.2310 \\
\hline CPL & Odds Ratio & Std. Err. & $\mathrm{z}$ & $\mathrm{P}>|\mathrm{z}|$ & \multicolumn{2}{|c|}{ [95\% Conf. Interval] } \\
\hline Social capital & 3.6922 & 2.5083 & 1.92 & 0.055 & .975 & 13.981 \\
\hline Local skill & 44.6555 & 46.9374 & 3.61 & 0.000 & 5.691 & 350.407 \\
\hline Local asset & .9253 & .4290 & -0.17 & 0.867 & .373 & 2.296 \\
\hline & $\begin{array}{l}\text { Social capital } \\
2.821\end{array}$ & $\begin{array}{l}\text { Local skill } \\
1.679\end{array}$ & $\begin{array}{l}\text { Local asset } \\
1.714\end{array}$ & & & \\
\hline
\end{tabular}

Figure 11. Result of Ordered Logistic Regression: Local Capacity - CPL

\section{Discussion}

Align with the arguments of Peredo and Chrisman (2006), the CBEs are indeed typically established in communities under socio-economic and political pressure. However, this paper identifies no significant influence of contextual constraints on community-participation. The motivation of community members to participate is more influenced by the local skill than by social capital. Not having the necessary means or assets to establish CBE is not hindering the community members to participate as long as they have expectancy that they are able to do so (possessing the underlying skill and social capital).

If the sustainability of CBEs is judged in terms of performance, it can be implied that the CBEs are sustainable. Generally the CBEs indeed bring economic, social, as well as environmental improvements, although the degree of improvements varies widely from case to case. Nevertheless, it would be too naïve to only judge the achievement, without considering whether the achievement is actually reached sustainably by the community or it is nothing else than the result of the old-paternalistic-approach. Another way of judging CBEs' sustainability is from their organization architecture, whether the CBEs are indeed "managed and governed by the people, rather than by government or some smaller group of individuals on behalf of the people" (Peredo \& Chrisman, 2006: 316).

This paper identifies that almost all CBEs' activities are not free from outsiders' involvement. In most cases, at least formatively speaking, the government provide partial or full supports to the CBE-framework and there are active NGOs (both international and local) supporting the communities. The NGOs are dominant in strategic activities (initiating the idea of and preparation for $\mathrm{CBE}$, and providing the necessary financial means), while the communities are dominant only in operational activities (undertaking the operational works and preparing the local materials). Therefore, although the analysis shows that the communities possess decision-making authority, the viability of this authority is questionable if the NGOs are absent. The author argues that the willingness and the physical means are not working independently. Considering the fact that in most cases the communities do not possess the necessary means to establish a CBE, it would seem to be difficult to establish CBEs solely on their own power (excluding the outsiders' intervention).

The finding of this paper does not significantly support the argument "the higher the CPL, the better the performance". The NGOs' participation-level is, on the other hand, significantly leading to successful performance. The 3-way-table below (figure 12) reflects that partnerships between communities and NGOs could perhaps offer a better option. Even with low or medium CPL, CBEs may become very successful when it is combined with high NGOs' participation-level. A more popular pattern is the combination of medium CPL with medium NGOs' participation-level. Without much supports from the NGOs, CBEs can also be very successful whenever the communities themselves really capable and highly participate in the CBEs. There is one exceptional case where it has high participation of both community and NGOs but unexpectedly achieves low performance; a further research is needed to prove that it is no coincidence.

Furthermore, regarding the community-representation, this paper finds out that in most cases, only leaders/elite-group members or selected 'ordinary' community members are dominant in performing strategic and 
decisional works. The majority of community members highly participate only in 'simple' works such as operational works and providing local materials. Unlike the argument of Peredo and Chrisman above, 'smaller group of individuals on behalf of the people' is in many cases still becoming the driver of CBEs.

\begin{tabular}{|c|c|c|c|c|c|}
\hline \multirow{2}{*}{ Community-participation-level } & \multirow{2}{*}{$\begin{array}{l}\text { NGOs' } \\
\text { participation-level }\end{array}$} & \multicolumn{4}{|c|}{ Performance category } \\
\hline & & 2 & 3 & 4 & 5 \\
\hline \multirow[t]{3}{*}{ Low } & Low & & 1 & & \\
\hline & Medium & & 3 & 1 & \\
\hline & High & & & & 3 \\
\hline \multirow[t]{3}{*}{ Medium } & Low & & 1 & 1 & \\
\hline & Medium & & 8 & 2 & 6 \\
\hline & High & & & 1 & 4 \\
\hline \multirow[t]{3}{*}{ High } & Low & & & 1 & 1 \\
\hline & Medium & & & & \\
\hline & High & 1 & & & \\
\hline
\end{tabular}

Figure 12. Participation-Level of Community \& NGO - Performance

Additionally, this paper tries to roughly combine the CBEs' legal form and the revenues they generate to get a picture if they have a certain pattern. Out of six CBEs registered as association, two have low revenue (<10 000 US\$) and four medium revenue (between 10000 and 1 million US\$). One out of six CBEs registered as commercial enterprise have low revenue, four medium revenue, and one high revenue (11 million US\$). One registered as cooperative has medium revenue. Meanwhile, six of those registered merely as an organization (without specifying the legal form) have low revenue and three medium. It seems that CBEs registered as commercial enterprise are slightly more successful than those 'association' CBEs and much more successful than those 'registered' ones. Further investigation is necessary to examine whether a certain legal form indeed has influence on the performance.

\section{Conclusion and Direction for Future Research}

Pursuing a sustainable CBE-model, this paper advances the knowledge regarding the CBE's organizational architecture and performance. The findings of this paper show a sustainable performance of CBEs since they indeed (to various extents) improve the economic, social, and environmental conditions at the local communities. However, the sustainability of CBEs' organizational architecture should be considered cautiously since outsiders' interventions can be found in almost all CBEs' activities and in many cases the CBEs are still driven only by a smaller group of individuals. It can be implied that community-participation plays an important role in the CBE, but not necessarily the sole important aspect in leading to the CBEs' success. Instead of putting efforts exclusively on increasing the degree of community-participation, planners and practitioners should have a system view and take into account the outsiders' roles. Given the diverse local conditions, more efforts should be made, especially at the beginning phase, to find the right combination of community-outsiders-partnerships, tailored to each situation.

Finally, this paper's findings should not be considered as an end but as a steppingstone, linking the existing knowledge and the potential knowledge in future research. Some research ideas may be raised from this paper; for example, an extension research using larger sampling-size or a comparative research to see if there is any differences between CBEs in developed and developing countries. The diversity of CBE's organizational forms identified in this paper can also stimulate a further conceptual research - structurally combining this form with existing organization forms such as cooperative and commercial enterprise. This way will show if this CBE-form is actually a new organization form or merely a hybrid of the existing ones.

\section{Acknowledgements}

I would like to thank the two anonymous reviewers for their comments and suggestions, as well as the DZ Bank Stiftung for the financial support during the study. 


\section{References}

Abu-Jarad, I. Y., Yusof, N. A., \& Nikbin, D. (2010). A review paper on organizational culture and organizational performance. International Journal of Business and Social Science, 1(3), 26-46.

Antinori, C., \& Bray, D. B. (2005). Community forest enterprises as entrepreneurial firms: Economic and institutional perspectives from Mexico. World Development, 33(9), 1529-1543. http://dx.doi.org/10.1016/j.worlddev.2004.10.011

Atkinson, J. W., \& Feather, N. T. (Eds.) (1966). A theory of achievement motivation. New York, NY: Wiley.

Child, J. (1972). Organizational structure, environment and performance: The role of strategic choice. Sociology, 6(1), 1-22. http://dx.doi.org/10.1177/003803857200600101

Chin, W. W. (1998). The partial least squares approach to structural equation modelling. In Marcoulides, G. A. (Ed.) Modern methods for business research (pp. 295-358). Mahwah, NJ: Lawrence Erlbaum Associates.

Chin, W. W., \& Newsted, P. R. (1999). Structural equation modeling analysis with small samples using partial least squares. In Hoyle, R. (Ed.) Statistical strategies for small sample research (pp. 307-341). Thousand Oaks, CA: Sage.

Dees, G. G., \& Robinson, R. B. Jr. (1984). Measuring organizational performance in the absence of objective measures: The case of the privately-held firm and conglomerate business unit. Strategic Management Journal, 5, 265-273. http://dx.doi.org/10.1002/smj.4250050306

Eisenhardt, K. M. (1989). Building theories from case study research. Academy of Management Review, 14(4), 532-550.

Evan, P., \& Appleton, B. (1993). Community management today: The role of communities in the management of improved water supply system, IRC Occasional Paper 20, Delft, The Netherlands.

Fafchamps, M. (2000). Ethnicity and credit in African manufacturing. Journal of Development Economics, 61, 205-235. http://dx.doi.org/10.1016/S0304-3878(99)00068-1

Fornell, C., \& Bookstein, F. L. (1982). Two structural equation models: LISREL and PLS applied to consumer exit-voice theory. Journal of Marketing Research, 19(4), 440-452. http://dx.doi.org/10.2307/3151718

Fornell, C., \& Larcker, D. (1981). Evaluating structural equation models with unobservable variables and measurement error. Journal of Marketing Research, 18(1), 39-50. http://dx.doi.org/10.2307/3151312

Fussel, H., Harrison-Rexrode, J., Kennan, W. R., \& Hazleton, V. (2006). The relationship between social capital, transaction costs, and organizational outcomes: A case study. Corporate Communications, 11(2), 148-161. http://dx.doi.org/10.1108/13563280610661688

Hair, J. F., Ringle, C. M., \& Sarstedt, M. (2011). PLS-SEM: Indeed a silver bullet. Journal of Marketing Theory and Practice, 19(2), 139-150. http://dx.doi.org/10.2753/MTP1069-6679190202

Hak, T., \& Dul, J. (2009). Theory-testing with cases, ERIM Report Series Research in Management. Retrieved from http://hdl.handle.net/1765/16206

Handy, F., Cnaan, R. A., Bhat, G., \& Meijs, L. C. P. M. (2011). Jasmine growers of coastal Karnataka: Grassroots sustainable community-based enterprise in India. Entrepreneurship and Regional Development, 23(5), 405-417. http://dx.doi.org/10.1080/08985626.2011.580166

Jost, P. J. (2000). Organisation und Koordination. Göttingen: Gabler Verlag.

Kanter, R. M., \& Brinkerhoff, D. (1981). Organizational performance: Recent development in measurement. Annual Review of Sociology, 7, 321-349. http://dx.doi.org/10.1146/annurev.so.07.080181.001541

Karki, M. (2001). Institutional and socioeconomic factors and enabling policies for non-timber forest product-based development in Northeast India, March, IFAD Report No. 1145-IN.

Kerins, S., \& Jordan, K. (2010). Indigenous economic development through community-based enterprise, Centre of Aboriginal Economic Policy Research, Topical Issue No. 06/2010.

Li, W. (2006). Community decision-making participation in development. Tourism Management, 33(1), 132-143.

Lucas, W. A. (1974). The case survey method: Aggregating case experience, Rand Report R-1515-RC, Santa Monica, CA, Rand Corporation. 
Mansoor, N., Aslam, H. D., Barbu, C. M., Capusneanu, S., \& Lodhi, M. A. (2012). Organizational structure as determinant of organizational performance: Uncovering essential facets of organic and mechanistic structure. American Journal of Scientific Research, 55, 48-55.

Manyara, G., \& Jones, E. (2007). Community-based tourism enterprises development in Kenya: An exploration of their potential as avenues of poverty reduction. Journal of Sustainable Tourism, 15(6), 628-644. http://dx.doi.org/10.2167/jost723.0

Mappatoba, M. (2004). Co-management of protected areas. Göttingen: Cuvilier Verlag.

Miles, M. B., \& Huberman, A. M. (1994). Qualitative data analysis: An expanded sourcebook. London: Sage.

Nadler, D. A., \& Tushman, M. L. (1997). Competing by design: The power of organization architecture. New York: Oxford University Press. http://dx.doi.org/10.1093/acprof:oso/9780195099171.001.0001

Nahapiet, J., \& Ghoshal, S. (1998). Social capital, intellectual capital, and the organizational advantage. Academy of Management Review, 23(2), 242-266.

Nooteboom, B. (2007). Social capital, institutions and trust. Review of Social Economy, 65(1), 29-53. http://dx.doi.org/10.1080/00346760601132154

Odero, K. K. (2004). Community-based enterprise: Their role in sustainable natural resource management and rural livelihoods in Zimbabwe, Proceedings the Tenth Biennial Conference of the IASCP, Oaxaca, Mexico, 9-13 August 2004.

Orozco-Quintero, A., \& Davidson-Hunt, I. (2010). Community-based enterprises and the commons: the case of San Juan Nuevo Parangaricutiro, Mexico. International Journal of the Commons, 4(1), 8-35.

Peredo, A. M., \& Chrisman, J. J. (2006). Toward a theory of community-based enterprise. Academy of Management Review, 31(2), 309-328. http://dx.doi.org/10.5465/AMR.2006.20208683

Powers, D. A., \& Yu, X. (2008). Statistical Methods for Categorical Data Analysis (2 ${ }^{\text {nd }}$ Ed). UK: Emerald Group Publishing Limited.

Putnam, R. D., Leonardi, R., \& Nanetti, R. Y. (1993). Making democracy work: civic traditions in modern Italy. In Anderson, A. R., \& Jack, S. L. (2002), The articulation of social capital in entrepreneurial networks: A glue or lubricant?, Entrepreneurship and Regional Development, 14(3), 193-210.

Rapley, T. (2013) Sampling strategies in qualitative research (pp. 49-63). In Flick, U. (Ed.) (2013) The SAGE Handbook of Qualitative Data Analysis. London: SAGE Publications Ltd.

Richard, P. J., Devinney, T. M., Yip, G. S., \& Johnson, G. (2009). Measuring organizational performance: Towards methodological best practice. Journal of Management, 35(3), 718-804. http://dx.doi.org/10.1177/0149206308330560

Rickard, S. (2006). The economics of organization and strategy. UK: McGraw-Hill Education.

Ruekert, R. W., Walker Jr., O. C., \& Roering, K. J. (1985). The organization of marketing activities: A contingency theory of structure and performance. Journal of Marketing, 49, 13-25. http://dx.doi.org/10.2307/1251172

Sammy, J., \& Opio, C. (2005). Problems and prospects for conservation and indigenous community development in rural Botswana. Development Southern Africa, 22(1), 67-85. http://dx.doi.org/10.1080/03768350500044644

Sandelowski, M. (2004). Using qualitative research. Qualitative Health Research, 14(10), 1366-1386. http://dx.doi.org/10.1177/1049732304269672

Scanlon, L. J., \& Kull, C. A. (2009). Untangling the links between wildlife benefits and community-based conservation at Torra conservancy, Namibia. Development Southern Africa, 26(1), 75-93. http://dx.doi.org/10.1080/03768350802640107

Schiffer, E. (2004). Community-based natural resource management in Namibia: How does it influence local governance?, Doctoral dissertation, Ruhr University Bochum, Germany.

Somerville, P., \& McElwee, G. (2011). Situating community enterprise: A theoretical exploration. Entrepreneurship and Regional Development, 23, 317-330. http://dx.doi.org/10.1080/08985626.2011.580161

Soviana, S. (2013). Case survey for assessing community-based enterprise: A research design, Working paper. Retrieved from http://hdl.handle.net/10419/84707 
Soviana, S., \& Kühl, R. (2013). Assessing community-based environmental management: coordination, motivation, and performance. International Journal of Environment and Sustainable Development, 12(1), 86-101. http://dx.doi.org/10.1504/IJESD.2013.051731

Stone, L. S., \& Stone, T. M. (2011). Community-based tourism enterprises: Challenges and prospects for community participation, Khama Rhino Sanctuary Trust, Botswana. Journal of Sustainable Tourism, 19(1), 97-114. http://dx.doi.org/10.1080/09669582.2010.508527

Teixeira, R., Koufteros, X. A., \& Peng, X. D. (2012). Organizational structure, integration, and manufacturing performance: A conceptual model and propositions. Journal of Operations and Supply Chain Management, $5(1), 69-81$.

The Economist. (2010). The political instability index. Retrieved May 25, 2014, from $\mathrm{http}: / /$ viewswire.eiu.com/site_info.asp?info_name $=$ social_unrest_table\&page $=$ noads\& $\mathrm{rf}=0$

Transparency International. (2013). Corruption perception index. Retrieved May 25, 2014, from http://cpi.transparency.org/cpi2013/

Venkatraman, N., \& Ramanujam V. (1986). Measurement of business performance in strategy research: A comparison approaches. Academy of Management Review, 11, 801-814.

Welsch, H. P. (2004). Entrepreneurship: The way ahead. London: Routledge. http://dx.doi.org/10.4324/9780203356821

World Bank. (2013). Poverty index. Retrieved May 25, 2014, from http://data.worldbank.org/

Yin, R. K. (2009). Case study research: Design and methods $\left(4^{\text {th }}\right.$ Ed). Thousand Oaks, CA: Sage.

Zoda, G., \& Zaheer, A. (2012). A network perspective on organizational architecture: Performance effects of the interplay of formal and informal organization. Strategic Management Journal, 33, 751-771. http://dx.doi.org/10.1002/smj.1966

\section{Notes}

Note 1. Whereas the term organizational design puts more emphasis on the activity of designing and organizational structure on the result of designing, organizational architecture covers both aspects and will be used consistently in this paper.

Note 2. Community is an aggregation of people that is not defined primarily by the sharing of goals or productive activities of the enterprise, but instead as those who share geographical location, ethnicity, and cultural identity (Peredo \& Chrisman, 2006).

Note 3. Aligning to earlier works in community-based management research, this paper categorizes the outsiders into three groups: the government, international and local NGOs/donor agencies (hereafter: NGOs), and private actors (Sammy \& Opio, 2005; Schiffer, 2004; Soviana \& Kühl, 2013). 